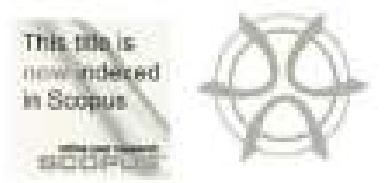

PLANNING MALAYSIA

Geospotial Anolysis in Urban Planning

Volume II (2013), Page 163 - 190

\title{
THE RELIABILITY TEST OF VISUAL LANDSCAPE FEATURES MEASUREMENT IN HIGHLANDS TOURISM PLANNING
}

\author{
Nafisa Hosni', Neoraini Yusoff ${ }^{1}$ \& Hairul Nizam Ismail' \\ ${ }^{1253}$ Centre for Inovative Planaing and Development (CIPD) \\ Faculty of Built Environment \\ UNIVERSITI TEKNOLOGI MALAYSIA
}

\begin{abstract}
Utilizing accessible data in objective measurement of visual landscape can assist planners and landscape architects to assess and understand the landscape in a technical sense. This approach requires minimal digital physical data provided by various agencies. As with this approach, the study tesis the validity of objective measurement in visual landscape using the photography method for perceptual testing in 48 test scenes. The correlations between these assessments are carried out; the result of which demonstrated that the measurement used in the study for visual landscape assessment is statistically acceptable for application with significant correlation $(p<0.01$ ) and moderate association (0.446). In the local context this study found that village is more preferable than other built up areas. The agriculture views which are dominated in the scene are preferable than the agriculture that present in the middle ground view only. It is also found the quality of the agriculture view is influenced by the condition and manageabie view, whereas the combination of forest and agriculture at the foreground and middle ground is less attractive. The study has provided more reliable objective measurement of visual landscape for highlands tourism planning.
\end{abstract}

Keywords: visual landscape assessment, visual structure analysis, urban planning, GIS application, highlands, tourism, and expert based assessment

\footnotetext{
'Senior Lecturer at Department of Grban and Regional Planning, Fuculty of Huith Environment, Universiti Teknologi Malaysia. Emäl: b-nafisa aluen.my (Coresponding Autios)
} 


\section{INTRODUCTION}

Visual landscape can be assessed through expert based or perception based assessment. The quality depends on the physical landscape features or the perceptual /experiential processes that particularly based on the knowledge in the human viewer.

This approach is favoured to the local government particularly in Britain, Australia and few in United. The approach is easy to practice, consume less time and inexpensive to conduct (Lothian 2000; Daniel 2001). But, in recent years, expert based assessment has been criticized for being in adequately reliable (Danicl 2001; Lothian 2000; Daniel and Vining 1983). Unlike perception based approach, typically, the assessment is conducted based on the individual's experience, not group's experience, Hence, the reliability of individual judgement of the expert becomes important (Palmer and Hoffman 2001). Furthermore, the judgements between different experts may be varying according to different person mind and feeling (Arriazza et al. 2004). In short, the approach was questioned for its reliability particularly on subjectivity. While stadies on vistal landscape assessment are common, few have been carried out using scientific method and criteria of objectivity and reliability. This paper attempt to scientifically test reliability of the developed objective measurement criteria in expert based approach.

On the other hand, the design criteria of objective measurement for this assessment are fundamentally developed based on the "human aesthetic value" which means as a representative of human perception on landscape. These basic human perceptions and values offer valuable hints as to how to proceed in turning the asscssment criteria into more objective measurement with scientific views and landscape in general. As they may acquaint us with, in effect the features are meaningful to the ordinary eyes. To the extent, the measurement in assessment criteria will provides more meaningful input in explaining why certain landscapes have been treasured in a technical sense. Principal and objective values in the expert based assessment derive subjective perception of what is beautiful. Conceivably, beauty is too profound to be fully understood by the scientific methods. However, it is possible to determine the physical landscape of visual and spatial characteristics as landseape constitute a particular form of beauty by its properties (Higuchi 1984).

The aim of the study is to prove the reliability of the expert based issessment on visual landscape. The assessment processes involved; a) Acquisition of accessible physical data from various agencies; b) Database development of visual structure and landscape features analyses for objective 
measurement of visual quality assessment; c) Viewpoint selection and feature landscape analyses (e.g. preparation for application in measurement criteria of physical visual landscape assessment); d) Photography methods for the perceptual testing of the visual landscape quality in the case study of Cameron highlands on the same 48 test scenes.

\section{Highlands's tourism and planning}

The resort areas, particularly in tropical Asia are located in the imposing mountain ranges and cooler latitudes, which have the high potential of outstanding sceneries with wild terrain in the hills and splendid Asian landscape (Robert 1979; Barbara 1998). These resott areas are renown not only for its beauty and distinctive character (Barbara 1998) but for its interesting history. The highlands tourism resort so called "hill station" particularly in tropical Asian countries was originated from the British colonial (Robert 1979; William 2006; Barbara 1998). These areas were built for health, relaxation and sanitary (Barbara 1998). The great hill station resort became one of the popular tourism places, which still existed in Pakistan, India, Sri Lanka, Burma, Malaysia, Indonesia, Vietnam and Philippines. These hill stations situated in the high plateau were built by someone who knew and appreciate the scenic beauty of the area where its character reflects their bomeland landscape sphere. As stated by the Robert (1979), the hill station was built by a colonist who had explored into the highlands during official expeditions or informal hunting trips.

By the end of Second World War, the hill station went into decline (Barbara 1998). During the postcolonial period, the hill stations have still been regarded as favourite places for retreat for elite group as well as European and Dutch tourist (e.g. Weng 2006; Barbara 1998). At present, the highlands became more of Asian than Western history (Barbara 1998). The old hotels and villas are conserved for the tourism attraction. The natural landscape of hillside gradually converted into agriculture, and urban land uses to cater for the local communities and tourist need. Hitl's station is losing its beauty, overgrown and overpopulated but still its unique character as hill station is remained (Barbara 1998).

\section{Hill Station in Malaysia}

As for Malaysia (in Peninsular Malaysia), the highlands tourism, particularly hill stations are located at Titiwangsa. These areas are the headwater catchment for main rivers and host diverse group of flora and fauna (Kumaran \&Aitruddin 2006). The highlands tourism was existed since British colonialism in Malaya (Mapjabil et al, 2007). In the end of 19th century, hill stations in Malaysia 
namely Cameron bighlands, Fraser Hills, and Penang Hills were built by British colonist In the British era, the hills were built as a resont filled with botanical gardens and plantations. The development of these areas proved that planning system for the highlands was started since 1900s. As for example Cameron Highlands was planned and ruled by the British District Oflicer where the area is under jurisdiction and provision of Sanitarily Board Enactment, in 1926. construction of roads and zoning system namely agriculture reserve, town centre zone, residential area, services centre, National Park, administrative atea and recreation area were introduced by Development Committee.

These areas have been slowly losing its beauty and image as proved by Aziz \& Zainol (2009) that highlands tourism destination had low perception toward its image. As scenic scenery is one of the important factors to altract tourist (Aziz \& Zainol 2009), visual landscape assessment in managing its beauty is significant in the tourism area (Zube et al. 1975). As for Malaysia, the challenges for the management of these areas are influenced by its character (remote and isolated area) (Aziz \& Zainol 2009). These remote areas are very sensitive environmentally that need special development attention. The steepness of the terrain, the uniqueness of its micro climate, and the sensitivity of rare wildife causes the areas are sensitive to change (Weng 2006). Without careful planning and manngement on the highlands area, the scenic landscape which is valuable for the tourism wills also loss its aesthetic value (Weng 2006).

\section{STUDY AREA}

'The study area also known as Cameron Highlands ( $\mathrm{CH}$ ) is located in the state of Pahang West Malaysia and is the smallest district in the state (Figure 1). It is 100 to 2031 meters above sea level and forms part of Titiwangsa Mountain Range. $\mathrm{CH}$ is well known for its diverse scenic landscape and one of the oldest and largest hill resorts in Malaysia (Mariapan ef al. 2008). It bas a complex terrain and mountainous landscape. 


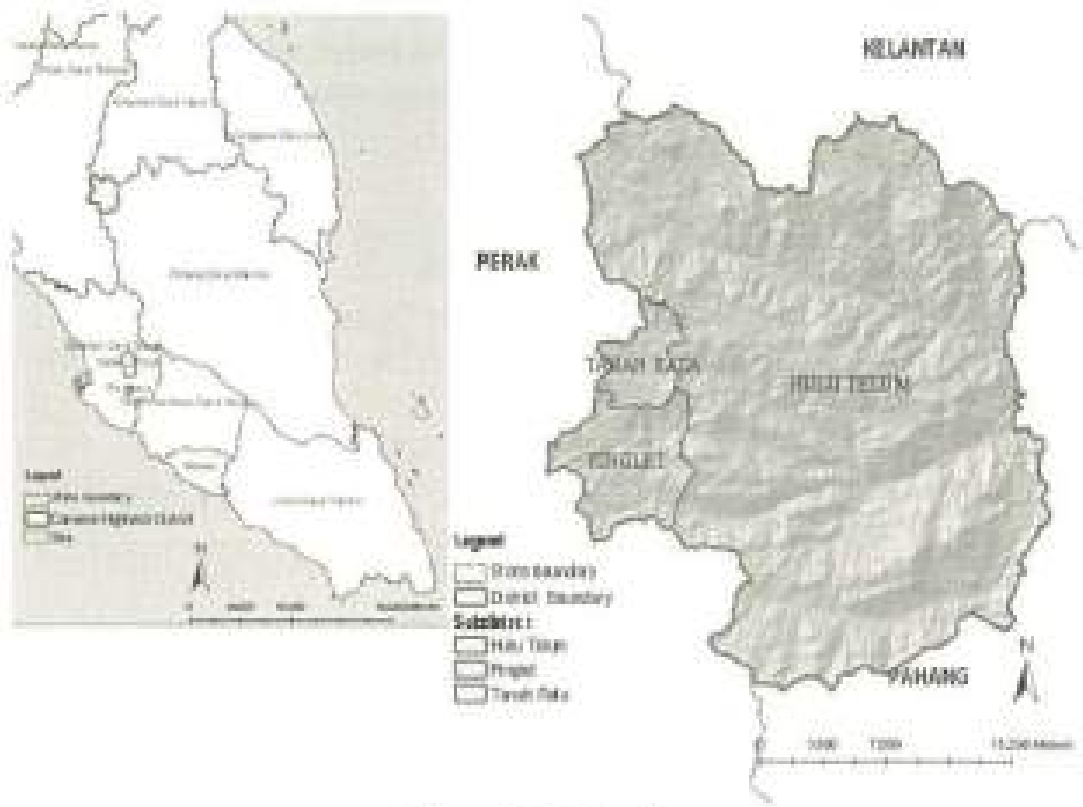

Figure 1: Study Arca

To the North of $\mathrm{CH}$ is the State of Kelantan and to the southeast, the State of Perak. CH covers an area of 72,218 hectares representing 2\% of Pahang State. It is accessible from the North-South Highway and Federal Highway II through Tapah ,Simpang Pulai road to Lojing and the Lembah Bertam to Kuala Lipis.

\section{SITE SELECTION}

There are several reasons to choose Cameron Highlands as a study site. One of them is that the district renowned for its natural setting and spectacular views. The Highlands tourism area, like other countries in the world, has a prominent fascinating panoramic view with outstanding land surface shapes. Alike to $\mathrm{CH}$, the main distinguished factor for its scenic beauty is the spectacular topographical profiles and cooling climate in the tropical country. The uniqueness of $\mathrm{CH}$ is also because of its history portrayed by the unique cultural landscape. This beauty of $\mathrm{CH}$ indeed was discovered and recorded since 1885 by the British surveyor in the colonial period. William Cameron and his companion, Kulup Riau in his mapping expedition of Titiwangsa Range described $\mathrm{CH}$ as "a vortex of mountains" with beautiful wide area of gentle 
slopes and plateau land of an elevation 4,400ft to 5,500ft. In Malaysia, the area is popularly known as the "green bowl" and cool hill station of a small slice of England deep in the jungle, Its beautiful landscape, fertile mountain slopes for planting and cool climates makes the area a unique tourism spot in Malaysia.

However, over the past two decades the rate of development has been uncontrolled. Buang (2001) affirmed that the CH is slowly dying and imperceptibly through the years:. While it has benefited the local economy, poor planning and enforcement have led to repulsive environmental degradation (Vijendra 2006). The envirommental degradation has influenced the landscape and visual quality of the study area whereas the visual landscape or scenic quality is encountered as a major component, particularly in the tourism or recreational area (Zube et al. 1982; Brown \& Daniel 1984).

The result has a strong correlation to the poor planning and lack of serious consideration on landscape and visual quality assessment in the strategic planning and decision making. This problem is a response to the lack of expertise and the tedious work with high cost to undertake. The urban and landscape planning management of the Cameron Highland District Municipal (CHDM) jurisdiction region is under a Department of Development and Landscape Planning. The department has no more than one expert personnel; planner officer and assistant planner to take control of the entire planning and landscape management in the district. The officer is responsible for planning control and landscape planning of the area and act as a development advisor to the developer and to the top management; decision maker.

The main existing consideration and reference for development advice used statutory and non-statutory plans/documents. The statutory plan is a gazetted local plan under a provision of Town and Country Planning Act, 1976 (A172 amendment 2001). The provision under the Act A721 stated the consideration of landscape in the planning control. The consideration that has been taken in the local plan described the neod of Environmental Impact Assessment (EIA) report in the sensitive area and the prohibition of tree cutting. The detail assessment on the landscape is included in the non-statutory plan. The non-statutory documents are including guidelines on highland development and Landscape Master Plan for the CH district. The guidelines, consideration and the assessment are available, yet no detail deliberations that emphasize the potentiality of the area for scenic qualities.

The traditional visual landscape quality assessment needs a comprehensive set process with tedious works. Exuessive workloads, high cost and impracticable evaluation for the planner to comprebend and interpret the 
result for the management and decision making process are not a wise approach to be practiced. The assessment needs to be practical, simple to understand by the planner and be able to be translated into management and development control. Since the consideration is already existed, the study area shows a great need for proper planning, opportunity and room for improvernent.

The main core activities of $\mathrm{CH}$ are forestry, agriculture and tourism. These economic activities only generate smalt annual revenue for the municipality. It is common practice in Malaysia that the major of Local Authority's (L.A) revenue comes from development and commercial building taxes. With small revenue and small number of expertise to manage the jurisdiction area has made the assessment unfeasible. Therefore, the landscape qualities keep on degrading and land use keeps changing. There is an urgent need for an action. Waiting for a right time with a perfect and tedious work requirement is simply not a better solution.

The scenic beauty consideration is needed as $\mathrm{CH}$ district's landscape is experiencing huge change in the land use (Mariapan et al. 2008; Kumaran \& Ainuddin 2004). The key to this problem is to utilize the existing resources. With this regard, the physical landscape study in the visual assessment will improve through more comprehensive area selection and desk study using available data provided by local government.

\section{DATA ACQUISITION AND DATABASE DEVELOPMENT}

\section{Data Acquisition}

The primary data consists of site survey and field work in the case study area. For the research, the data collection involves:

a) Interview officers from relevant agencies on the geospatial data development, availability and accessibility;

b) Field work study using photography method to collect the landscape scene in the chosen point along the existing road. The points were depicted from the road map with geo reference based acquired from the Pahang State Public Department and;

c) The respondent assesstnent on the photo landscape scene using assessment sheet on scoring scales.

The main secondary data acquired from the various agencies. The easily accessible data that can be utilized in the assessment area is mainly from the site 
planning datia from the Town and Country Planning Department and supported by other technical departments. The relevant easily aceessible data for landscape assessment of the case study (Cameron Highlands) are land use map; road map; historical data point; mountain data point; landform types and slope analysis data; river map; tourism attraction points map, and town centre point map, all with common scale of $1: 6336$ and topognaphical data map with scale of l:50,000.

Other data including written report and plan have been collected from planning and various technical departments in the different levels (Federal, State and Local) such as Malnysia Plans, National Physical Plan 206/2, Pahang State Structure Plan, Cameron Highlands District Local Plan 2005-2015, Technical Report of Cameron Highlands Local Plan 2005-2015 and Technical Report of Cameron Highlands Landscape Master Plan 2007. The details report for the case study is significantly used to support objective visual landscape assessment in the research.

The database for visual landscape assessment was designed and developed to support visual structure and landscape features analyses in objective measurement. In the study, there are two types of data namely. topographic data and landscape features data within the database. It is developed based on the conceptualized GIS to application of visual landscape for case study area. The gathered data is stored in its primiry form, where analysis can be readily prepared for more quantitative and rational based on its need.

\section{METHOD}

\section{Viewpoins Selection in GIS Application}

The selected observation point and input surface (e.g., DEM; TIN data) are used as a baseline in measuring visual landscape quality. The viewpoints were selected along the landscape corridor (existing main road). The selection was done using the digital road lines map and attraction points. The selected viewpoints deployed in between I $\mathrm{km}$ in distance. The further selection of 48 test scenes was made based on the viewpoints and direction views. These views were then applied on the ground using photography method. 


\section{Fieldwork-photography Method}

The photography method used for the validity test in perceptual test as the method valid and acceptable in landscape assessment from established literature (e.g., Torres et al, 2007; Hull \& Stewart 1992). The photographs are taken with a height of $1.5 \mathrm{~m}$ in the selected view point along the existing road. The determination of the point is based on the objective assessment score result that includes from high to low visual quality. The photograph by slide method of analysis was employed in the 48 scenes. Slides were presented to the small group of respondents who have no background in the related landscape and design knowledge. The respondents participate voluntarily in the assessment. Instructions were given to the respondents $(\mathrm{N}=44)$ that referred to the individual perception on the scenes with a judgement on the attractiveness and uniqueness. The respondents were given a brief orientation to the region. No discussion or explanation of important landscape features influences the assessment was presented. The respondents were required to rate scenic beauty of the selected landscape scenes on 5-point scales to facilitate respondents in giving a definite judgement on rating. The adopted Likert scale applied in the research wus outlined as 1 is not attractive; 2 is less attractive; 3 is medium attractive; 4 is attractive and; 5 is very attractive. The 10 point scales applied in the physical landscape features for expert assessment is unsuitable to be adopted in this preference study as it creates indistinguishable rating judgement to the respondents. The photo scene slides shows were presented one at a time for approximately 10 to 15 seconds per slide.

\section{Physical Landscupe Features Assessment}

Visual structure of landscape analysis in measuring the visual landscape involves distance zones, Viewshed analysis, visibility, angle of elevation, and angle of depression. As for the distance zones, the study accepted view is divided into three distances namely foreground (short distance view), middle ground (middle distance view) and background (long distance view) (e.g, Zube et al. 1984; Litton 1972; Craik 1972; Appleton 1975; Higuchi 1984). For the case study, the tropical rain forest tree top height is considered as dominant and common tree. An intermediate zone (canopy) of continuous foliage is 9 to 18 meters (30 to 60ft) (Federal Department of Forestry 2008; Kumaran \& Ainuddin 2004). As for the GIS application, the distance analysis is conducted using the proximity analysis (multiple ring buffers). The three distance zones are set using buffer distance value determined from the viewpoint as input features. The Viewshed analysis in the study determines which space is visible to an observation point. The first step for the calculation of visibility analysis is 
through the use of the 3D analysts for Viewshed analysis tools. The selected observation viewpoints and input surface (TIN data) are used as a base line for this analysis with an appropriate output raster based $10 \mathrm{~m}-$ square to $30 \mathrm{~m}$-square for local context. Meanwhile, the derivation of the angle of elevation, angle of depression is based on the GIS application.

The result of the Vlewshed analysis using GIS 3D analyst is in raster format. Then, the data was converted into vector format data. This data was overlaid with a GIS proximity analysis result to understand the distance dimension in visual landscape. Afterwands, line of sight analysis will be used for calculation of angle of elevation and angle of depression.

The angle of elevation for visual landscape analysis is applied to understand the acsthetic value of mountainous landscapes (Figure 2). The appreciation this landscape is based on the decisive degrees of angle of elevation. Himeno et ai. (1999) affirmed the effect of distance from the observer to the landscape elements can create massive, inviting or feeble impression. Higuchi (1984) introduced the range of angle of elevation is suitable for mountainous landscape viewing that give positive impact to visual quality.

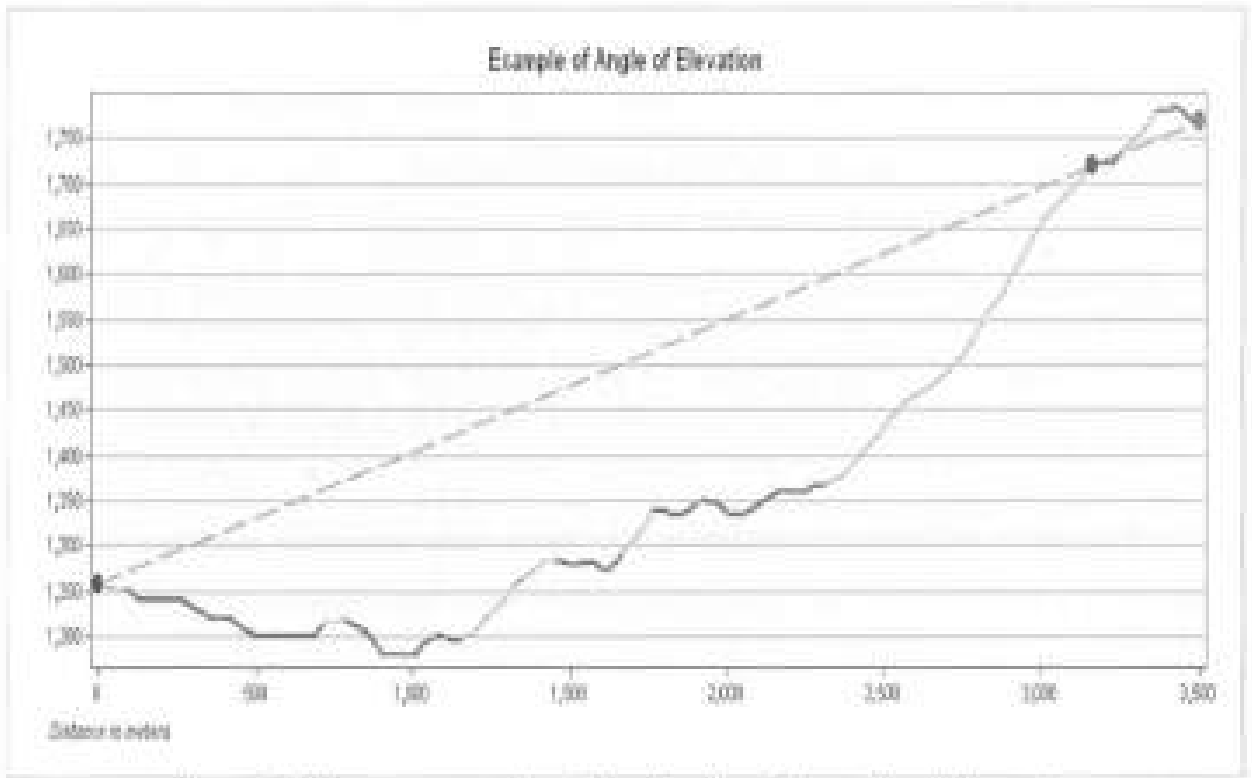

Figure 2: The cross-section of land surface for angle of elevation 
Meanwhile, as for this study, the angle of depression is appropriately applied for water elements (lake or dam) and deep valley near to the observer (Figure 3). The limit of angle of depression is when the point of incidence approaches the eye with 30 degrees (Higuchi 1984). The important use of angle of depression is to determine the distance feeling and openness. The appropriate use of this analysis is identified through the landscape types (i.e., mountainous landscapes and waters capes) and its concavity. The observer height set in this study is 1.5 meters. The baseline data for the line of sight analysis is $30 \mathrm{~m}$ TIN data (naked earth) without considering small features that may impede views.

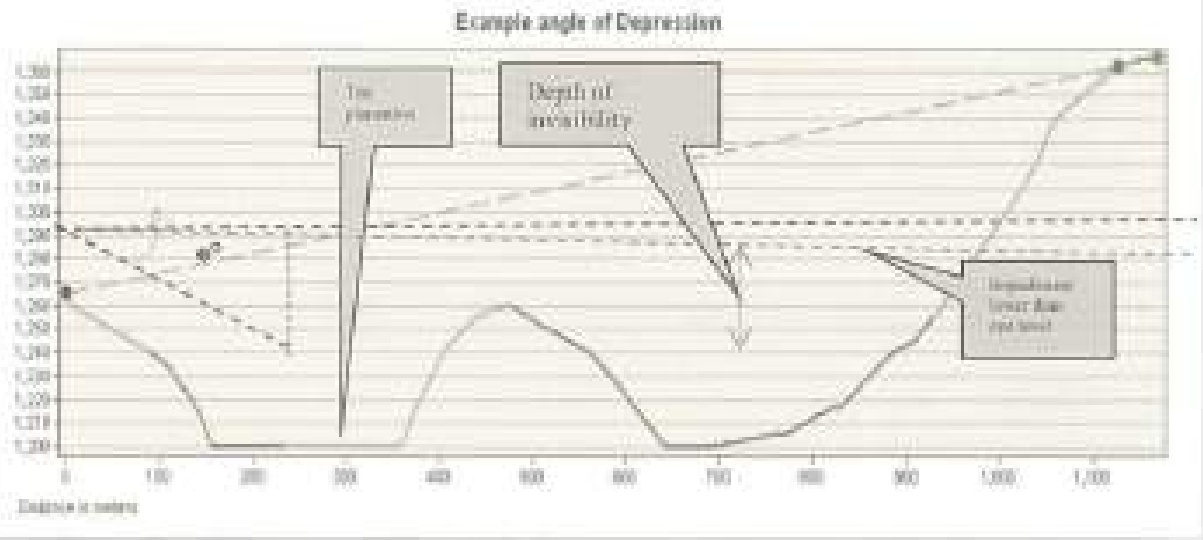

Figure 3: The cross-section of land surface for angle of depression

The analysis and measurement method in the study with regard to expert based approach and input from established perception based approach is on the landscape elements in the visual assessment. Few modifications are made to suit different available data and characteristic of the study area. The fundamental used in the study involves a combination of visual structure of landscape and the visibility of landscape features in the scène.

The criteria are derived from the consideration of landscapes (vegetation), presence or absence of water, topography and the sign of a human being. Principle of physical landscape structure was used in the study to develop more explicit and objective measurement criteria. The criteria were divided into seven elements with 4 given rating categories namely high, medium high, medium and low. The calculation of rating has taken consideration on the direction view and visibility in the viewpoints. The foundation elements used in the evaluation is almost the same as to the photograph assessment. The Likert's scale is used to give the rating score to each of the landscape elements in the measurement criteria table. The seale is given from 1 to 10 divided by four 
categories. Six elements except scarcity are summed and calculated to get an average score. The scarcity value is suggested to be isolated from the calculation and used for recond and reference only.

\section{Justification on Topography and Landform}

Lothian (2001) has classified the landform types in the study area by the scene in the photograph. As for this study, the digital data of the landform types (vector format data) and TINs data model (from digital contour lines data) are used to derive landform elassification analysis as well as the landscape compositional types (coneavity). The topography character is identified through elevation profile, DEM data and line sight analysis, The elevation in the study area is from $0 \mathrm{~m}$ to 2100 meters. From the casc study. there are six types of landform exist in the study area namely valley, ridges, saddles, mountain, hill and summit. Through the line sight analysis, the shape of the landform can be identified including u shape, concave, eonvex and variety through their prominently visible shapes. The rating eriteria are classified throughout topography profile wherein it is becoming more interesting as it gets steeper or more massive, or more severely or universally sculptured. Other important criteria in topography are mountainous background with consideration on the angle of elevation.

\section{Justification on Vegetation}

Vegetation is classified as described in the land use data types. The man made elements is categorized as urban uses. The primary consideration in rating criteria for vegetation is natural sentings, fea plantation area as well as other agriculture or the combination of them that ereate variety of form, pattem and textures. The existence of vegetation/land use diversity also has at close relationship distance views which gives a significant quality as well as landform, topography profile (angle of elevation and depression).

\section{Water Element}

The selected river line's data in the analysis is based on the main river tines. The presenee of lake/water body in the land use data set is also being taken into consideration in the assessment. The judgement of the water's presence includes the degree of water dominates the scene. It is identified through the shape (winding or straight line) (Appleton 1975), distance perception views (Appleton 1975) and the sum of appearance (Herzog 2003; Appleton 1975). 
The angle of depression gives a visual relationship between the surfaces of the water body. The relationship is strong when the angle is 10 degrees or more and loses its clarity when it reaches 2 degrees (Higuchi 1984). However, an angle of depression in 30 degrees makes the surface appears to be near and give a sense of unease for fear of falling (Higuchi 1984).

\section{Positive Element}

The positive element is recognized by land use description and reference to the local plan report. The rating consideration is on the importance's level and distance views. The consideration will indicate to which positive elements dominate the scene or not.

Consideration of uniqueness based on the presence of positive element, distance zones and landscape environment settings. The assessment on scarcity is to give a written justification of the scenic features that is rare or unique in the study area. The rating is elassified by the degree of rarity and the opportunity for viewing in the study area,

The important value of landscape elements for cultural and historical features is solely depending on the local character of the area. These elements can be identified through the input from relevant reports and plans. Noteworthy scenic scenery that has been stressed out in the Cameron Highlands District Local Plan and the Technical Report of the Landscape master plan 2007 case studies of Cameron's highlands is identified as below:

a) forest landscape has a high value in the region as most of the area gazetted for the reserved forest and has a historical value;

b) Agriculture land in the study area has special influence to the scenery, particularly in the valley area;

c) The most famous and outstanding view is tea plantation area in this region characterized by the upper ranges and valley area;

d) The notable special character of social value in the aboriginal settlement in which has a close relationship with the nature; other historical and cultural buildings that are significant to the case study area as stated in the Local Plan.

c) The aesthetical value of aboriginal settlements and tea plantation area in the visual quality for tourism also has been stated by Clifton $(2006)$ and Fui et al. (2006). 


\section{Negative Element}

The rating for the negative elements takes consideration on the distance perception views and the degree of the element dominates the scene. The element is identified by using land use data set and description of land use types. The element that gives visual shocking and intrusion to the scene such as dumping area, substation is categorized as a negative elenent.

\section{EXAMPLE OF TECHNICAL SENSE UNDERSTANDING}

The analysis is able to identify the potential of horizontal plane view from visual corridor such lake and flat plain. From the analysis, I point was plotted near to the Habu Lake. This point was at the Lake House.

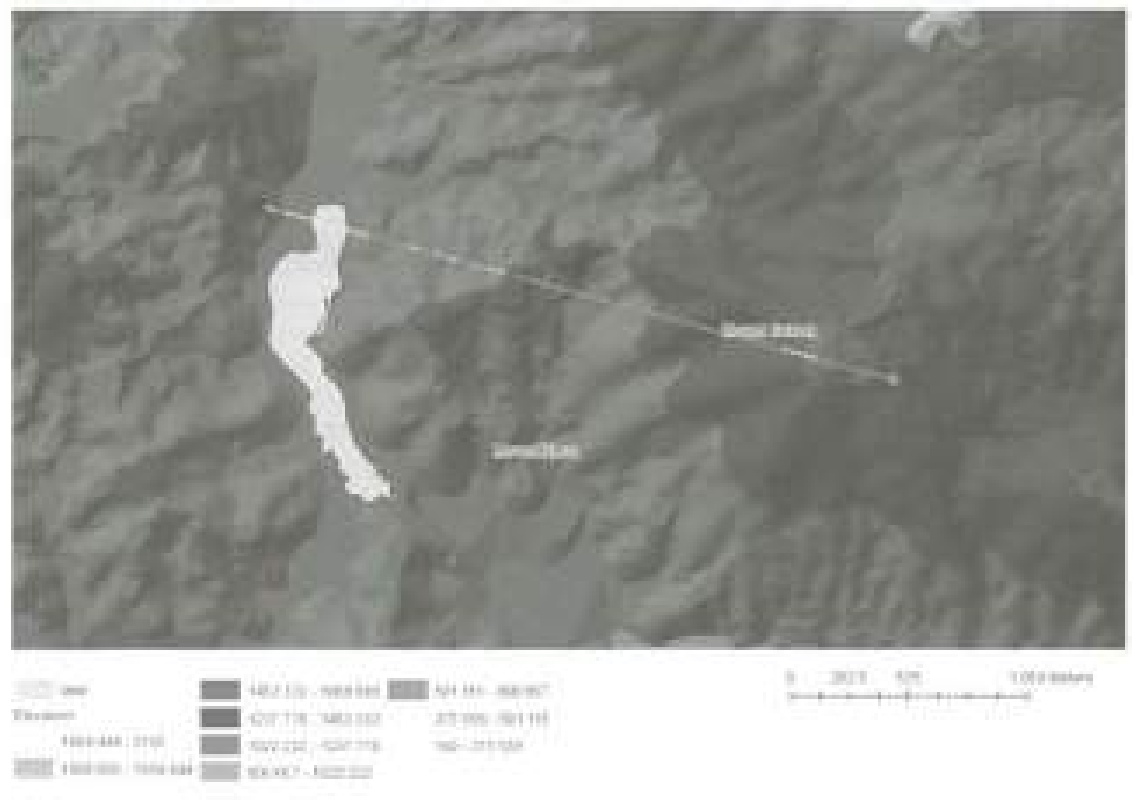

Figure 4(a): Line of sight analysis from Lalke House to Lake Habu using ArcMap 


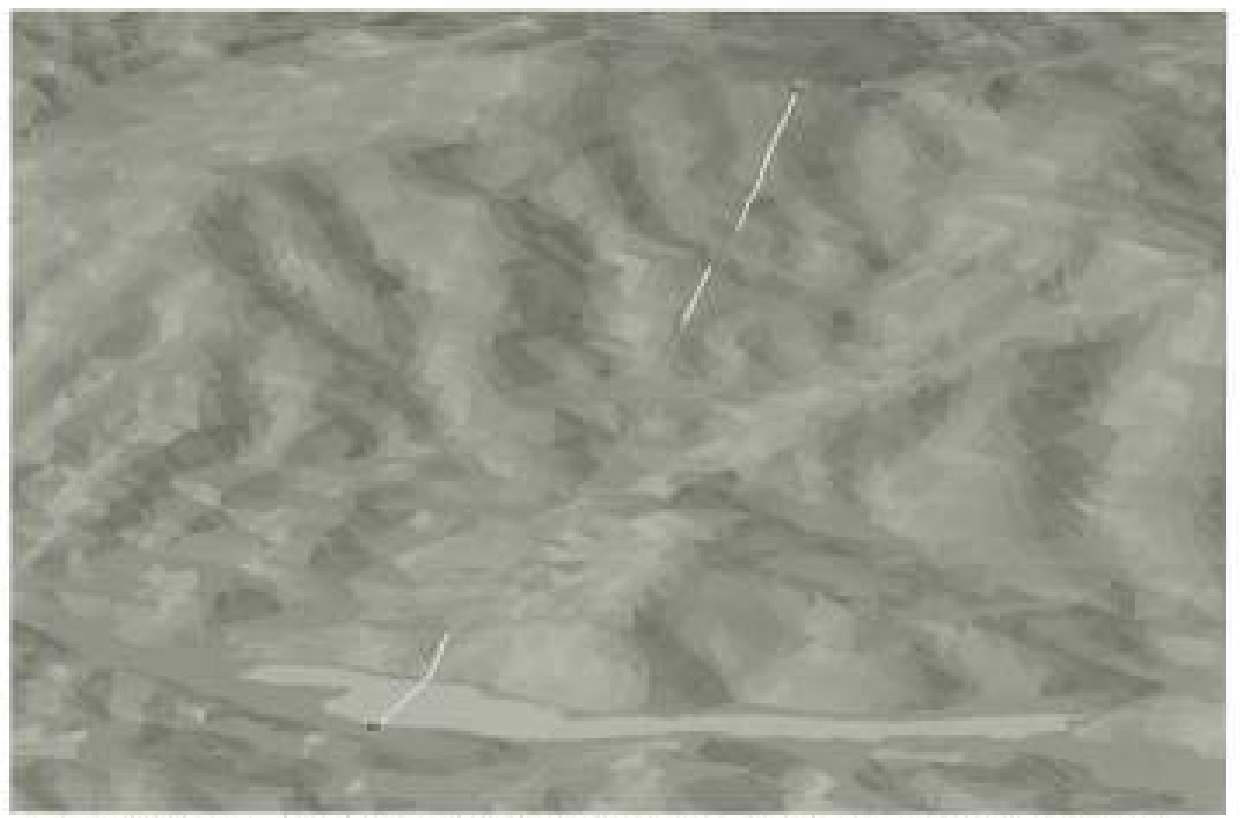

Figure 4(b): 3-dimensional view of Habu Lake to the background using AreScene.

\section{Intatake}

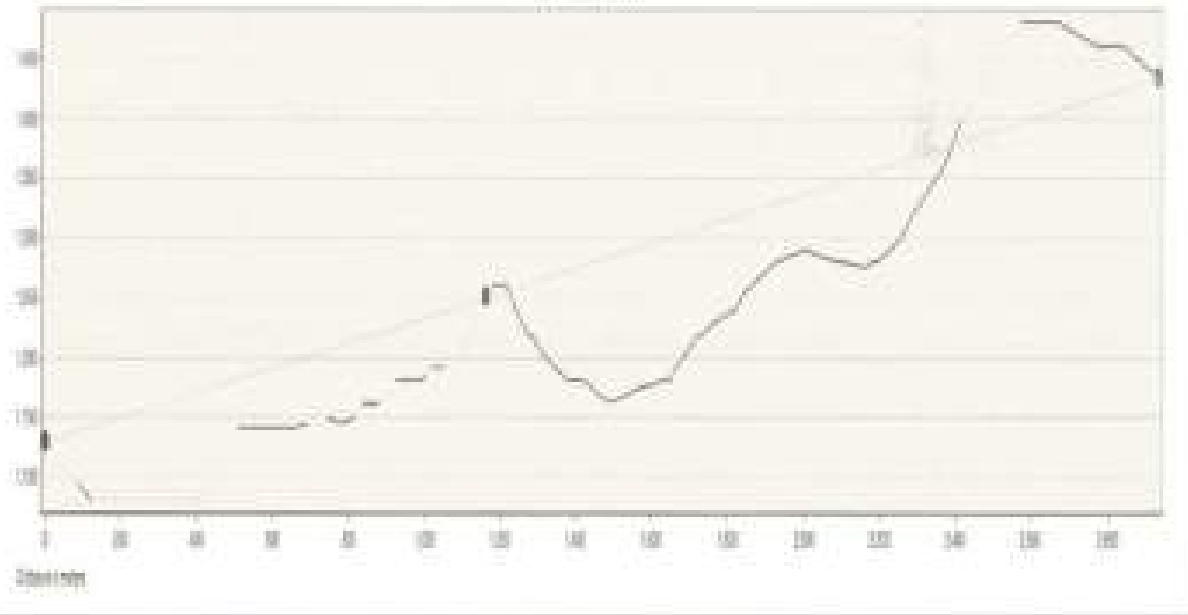

Figure 4(c); Topographical profiles of Lake House's view

We select one of the points situated at Lake House which confronting Lake Habu Lake. As refer to the Figure $4(\mathrm{a})$ to $4(\mathrm{c})$, the analysis shows the angle of depression of the point is about 21 degrees with 200 meters distance from the lake. The result demonstrates Lake House present a wide angle of 
incidence enough to the viewer. The large angle of depression with the eye level being raised to 30 meters height will give a feeling of openness to the viewer. The background view of the lake is mountainous landscape with angle elevation of 6.5 degrees which is pleasing for viewing (Higuchi 1984). It is showed the existing Tudor style resort of Lake House was built properly by someone who understood how impressive the lake and overlapping forested mountain view of Mount Kacu would look on the hill station with large angle of incidence.

The amalysis of the horizontal surface explicitly showed the useful information that can be documented for the purpose of field works and planning. The detail analysis of physical features using the accessible data not only can be documented but also capable in explaining the characteristic of landscape structure,

\section{VALIDITY TEST: PERCEPTUAL TESTING}

The study describes the distribution and correlation between the preference study analysis and the physical features based assessment. The calculation for correlation makes uses the Pearson's eorrelation eoefficient. 48 scene slides were used in the study. The same evaluation based on the expert measurement criteria in the assessment is applied using the scencs of the preference study obtained from the viewpoints and direction of view. The goal was to test the validity of the propose assessment. It was determined if the landscape features' assessment, could produce the similar result to the public preference for visual landscape quality assessment in the case study of Cameron Highlands.

The 48 direction views were subjected to an expert assessment using objective measurement criteria supported by physical landscape feature analysis. The Liker scale was applied in the assessment to assign the rating value from 1 to 10 . Meanwhile, for the perceptual testing, the same scenes were presented to the group of students from Universiti Teknologi Malaysia. A byslide method (Brown \& Daniel 1984; Clay \& Smidt 2004) was employed in the testing. The given scale is from 1 to 5 , with the lowest value (1) indieates not attrielive to the highest value (5) indicates the most attractive. The range of rating scale for perceptual testing is smaller than physical assessment scale. The reason is to ensure the observer bave easy and explicit judgement on the rating scores. The examples of highest rate visual landscape are shown in Figure 5. while the lowest rates are shown in Figure 6. 

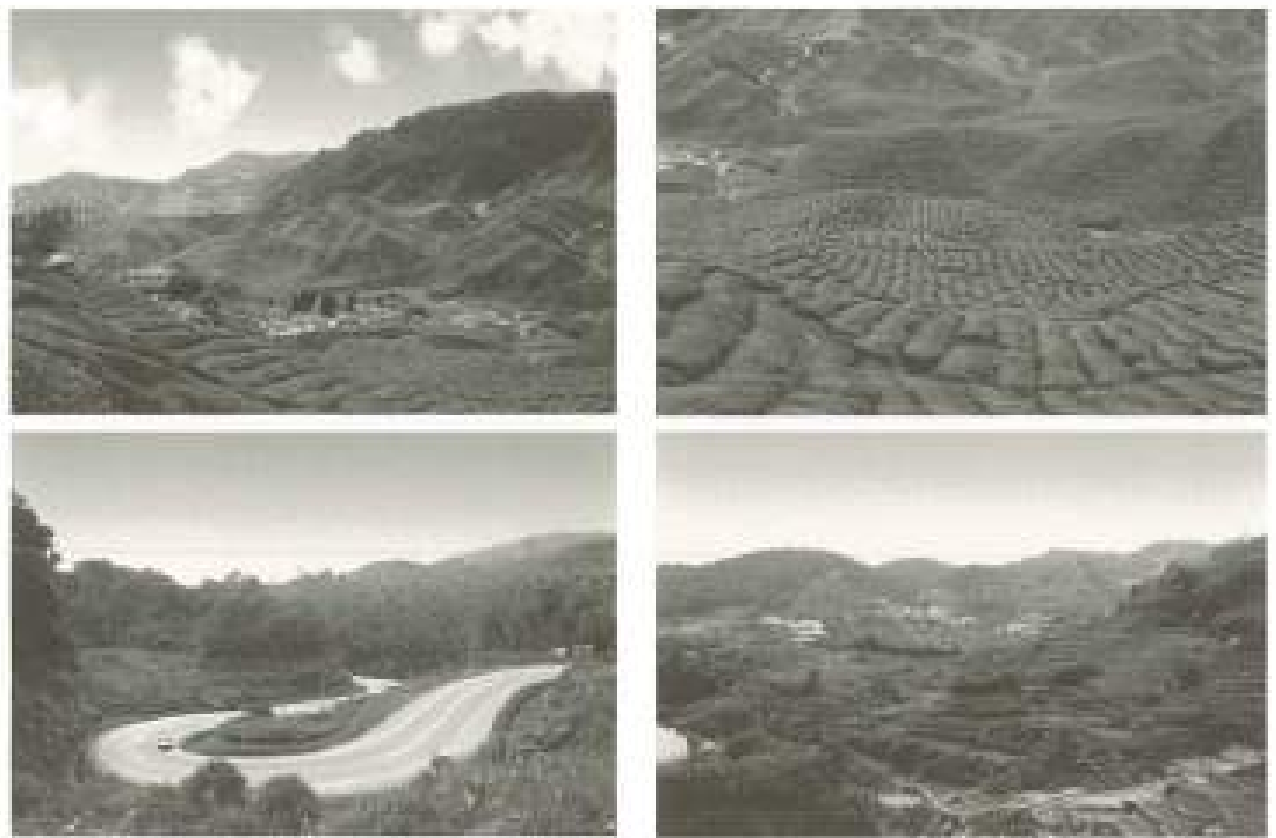

Figure 5: Examples of the Highest Rated Slide of Visual Landscape Quality

The successive interval method is applied in the analysis. It is used to obtain interval measures from ordered category data (Bliskche et al, 1975). The calculation involves the computation of frequency, proportions, cumulative proportions, conversion, standard normal deviates ( $\mathrm{z}$ scores), density function of probability, seale value and interval data value. The calculation is computed using excel software. The tabular datu is keyed in into SPSS statistical software that includes mean score and standard deviation. The percentage of distribution of preference score will address key indicators for the improvement of the measurement criteria development developed for the visual landscape assessment. 

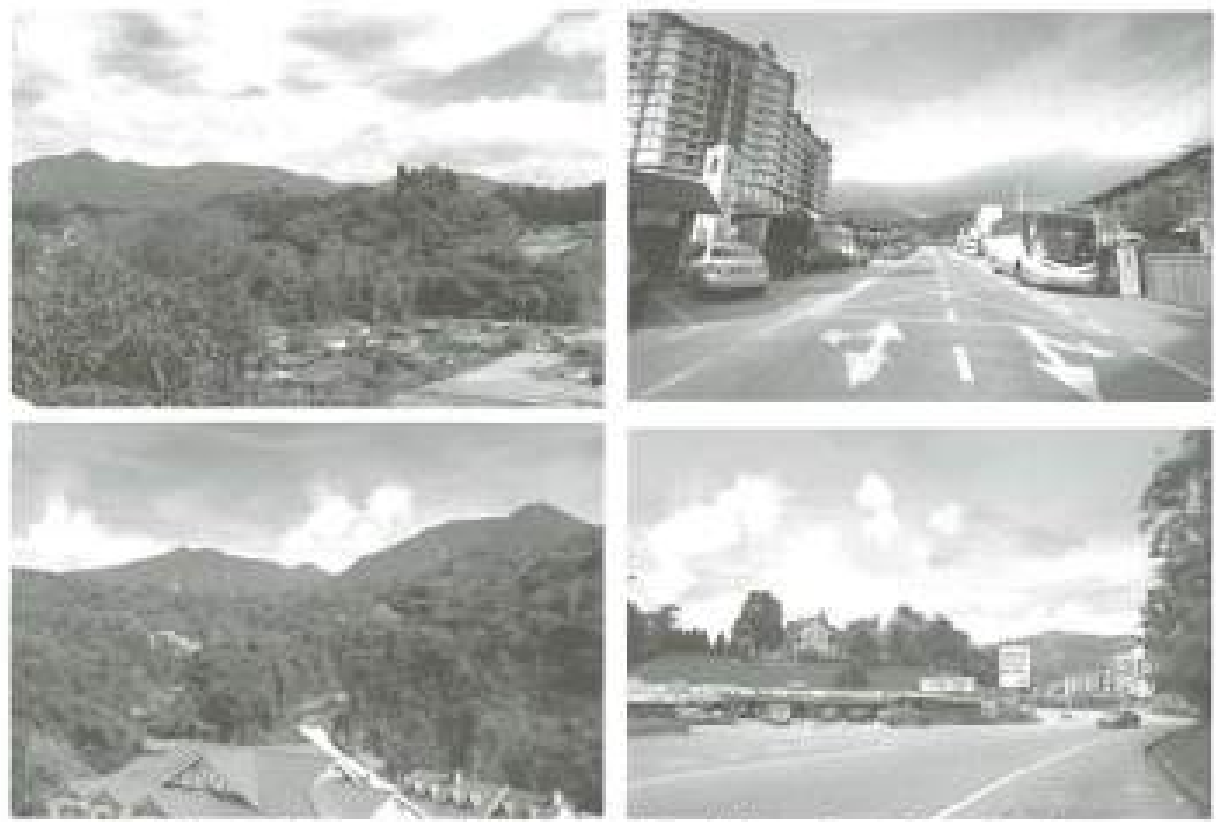

Figure 6: Examples of the Lowest Rated Visual L andscape Quality

The association of objective measurement criteria score's result and preference study (photography method) is analysed to verify the reiative eonsistency of value to the same scenes. The correlation's analysis is prepared in the SPSS statistical package to prove the reliability of the physical assessment through association correlation and Pearson significant result. The comparison analysis will demonstrate an association of given criteria to surrogate the photography methods to record the preliminary assessment data before field work study.

\section{RESULTS AND DISCUSSIONS}

\section{Correlations}

The relationship of the physical assessment and perceptual response to the scene was conducted. The study describes the correlation between the preference study analysis and the physical assessment seore. The calculation of correlation used the Pearson correlation coefficient. 
Table 1: Correlations of Perceptual test and Physical Based Assessment

\begin{tabular}{|l|c|c|}
\hline Landscape features & Pearson Correlations & Sig \\
\hline Preference \& Physical & $443^{*}$ & .000 \\
\hline Rating \& Uniqueness & $610^{*}$ & 000 \\
\hline
\end{tabular}

An examination of correlations between the physical assessment and perceptual test of scenic beauty shows a moderate association between rating and physical features. The correlations proved to be significant $(\mathrm{p}=, 000$ with significant at 0.01 levels) as shown in Table 1. This showed that the physical assessment in this study is sufficiently acceptable to give planners or landscape architects reasoned and objective judgements to visual landscape quality. It is identified also that the attractiveness has a strong association with uniqueness of the scene. This suggests that as the score of attractiveness is increases, correspondingly people will give a high score to unigueness of the scene.

Table 2: Correlations of Physical features

\begin{tabular}{|c|c|c|}
\hline Landscape features & Pearson Correlations & Sig \\
\hline Topography & $.527^{11}$ & .000 \\
\hline Landform & $.572^{21}$ & .000 \\
\hline Vegetation & $297^{\circ}$ & .020 \\
\hline Positive element & $.733^{\circ}$ & .027 \\
\hline Water element & .919 & .159 \\
\hline
\end{tabular}

Further examination was conducted using correlation analysis between perceptual response to the scenes and landscape features/attributes rating score from the physical assessment.

The result of correlations and associated $P$. values are presented in Table 2. The strongest ussociation is the water element $(0,919)$ follows by positive element ( 0.733$)$, landform $(0.572)$, and topography $(0.527)$. The lowest associations are vegetation $(0.297)$. However, it is significantly correlated with $P=0.02$ at 0.05 level of confident. It is also found that all the features have significant correlation except for water element and positive element.

\section{Perceptual Tests}

The study also demonstrates a limitation through the perceptual testing of same scenes. Even though the measurement approach proved to be reliable, yet some issues should be addressed. Firstly, the physical assessment could not show the detailed present of the visual quality conditions of the area. Secondly, the 
judgement on the vegetation cover should be done thoroughly as the correlation between these features is weak $(0.27)$. The respondents showed a different pattern of attractiveness of scenes by various vegetation covers. The natural setting proved to be a favourable scene to the respondents. However, the combination of forest and agriculture in the scene was seen as less attractive in comparison to the agriculture scene only. Additionally, the village setting received $\mathrm{a}$ higher score as compared to the residential area follows by the urban land uses.
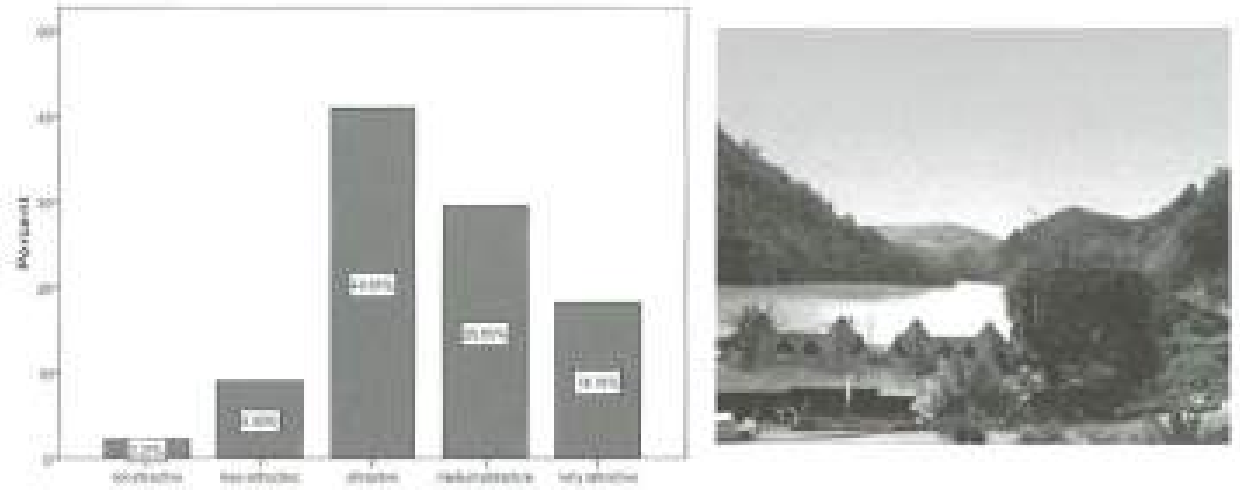

Figure 7: The Distribution of Perception Analysis and Test Seene at Lake House, Cameron Highlands (Mean 3.52)

Figure 7 shows that the score mostly falls in rating value 3 - attractive scene $(40.9 \%)$. Meanwhile, about $29 \%$ of respondents agreed the scene is medium attractive follows by very attractive (18.2\%). From the distribution analysis, it is also found that respondents feel the seene is not attractive $(2.3 \%)$ and less attractive $(9.1 \%)$. However, based on the physical assessment, the scores lie on the highest quality rank $(7,8)$. This suggests the dominance of water presence in the scene is strongly giving positive influences to the scenic beauty value. Nevertheless, people tend to reduce its value, control by the condition and quality of water (colour). The water perception value is strongly depending on the current quality condition of the water. 

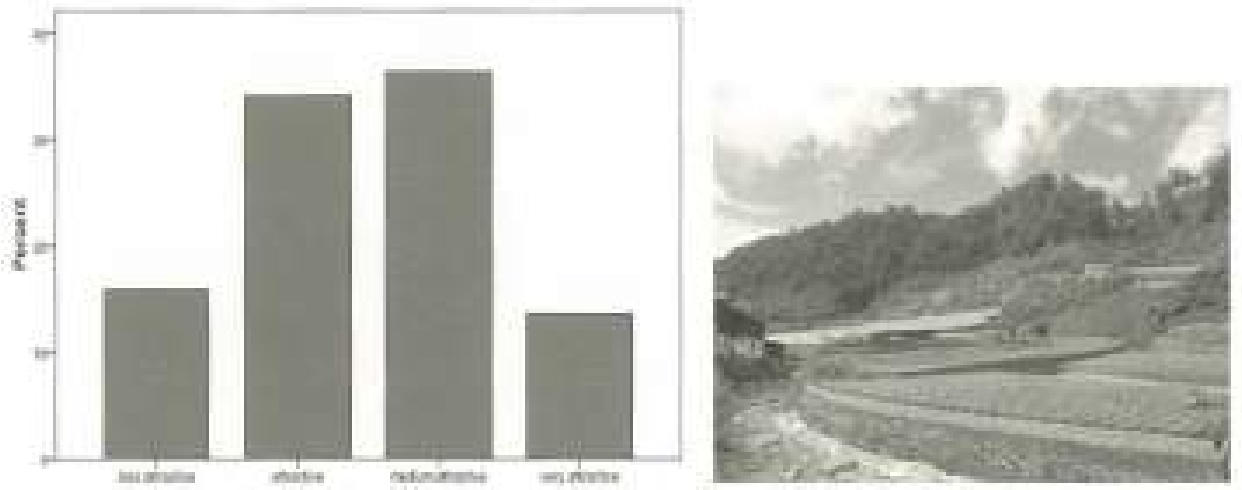

Figure 8: Distribution of Perceptual Test and Scene at Point 20 (Mean=3.48)

Figure 8 shows the scene with the presence of the water elements. The element majorly presents in the foreground with moderate dominancy in the scene. The water condition (colour) is average. From the distribution graph of perception analysis, most of the respondent agreed that the score is 4-medium attractive $(36.4 \%)$. This follows by attractive rating $(34.1 \%)$, less attractive $(15.9 \%)$ and very attractive $(13.6 \%)$. The analysis also approved that water condition influences the soore rating. The average water condition in the scene may influences the score lies to medium attractive score rather than attractive. However, the unalysis shows the large number of less attractive (15.9\%) as compared to the scene at Lake House. This suggests that the dominance of water presence as described in the measurement criteria of physical assessment tends to affect the score value. The physical evaluation indicates the scene has a moderate score in topography (6), landform (6) and vegetation types (6.7). These feature considerations affect scene's score value. 

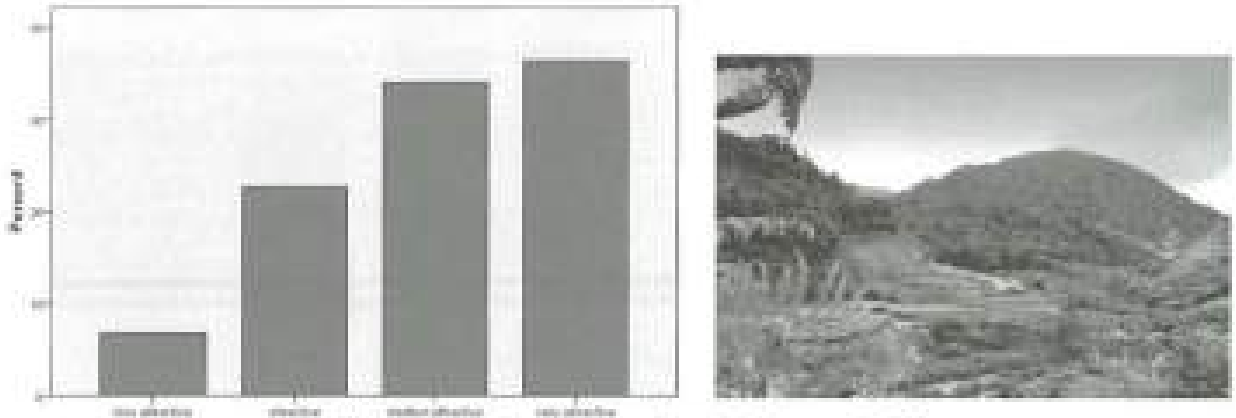

Figure $9(a)$ : Secae at point $9($ Mean $=2.95)$


Figure 9(b): Scene al point 28 (Meam=4.00)
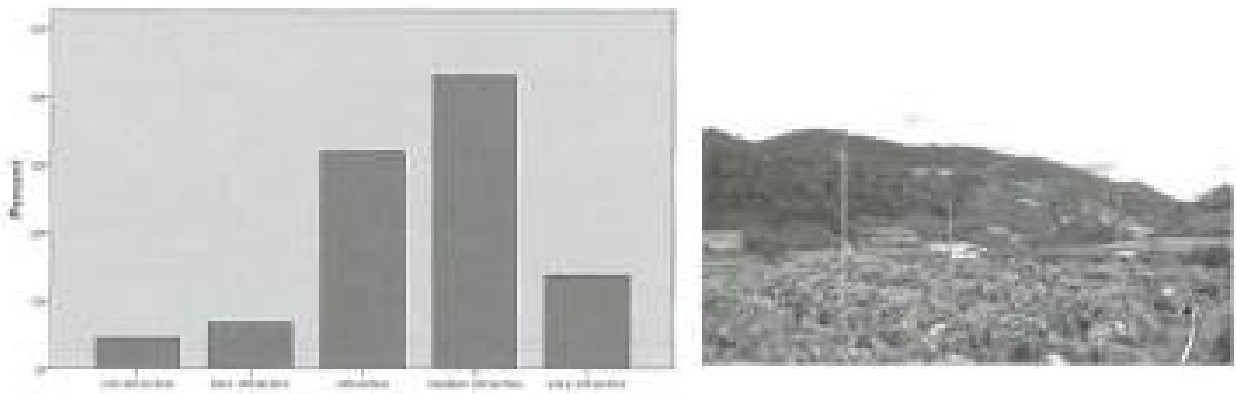

Figure $9(\mathrm{c})$ : Scene at point 18 (Mean 3.55)

As for vegetation, we generate the distribution graph of responses to the scene. The three scenes show the presence of agriculture land use (vegetables farm) in the fore ground and middle ground. As for the analysis, it is found that the presences of agriculture land use may increase the rating score of the scenes. As for both scenes have a high score with a scene at point 28 (mean- 4.00 ) and 
scene at point 18 (mean is equal to 3.55), refer to Figure 9. However, as we can see the combination of secondary forest and agriculture for the scene at point 9 (mean=2.99) affects the feeling of less or not attractive with responses score of less attractive $(29.55)$ and not attrictive $(6.8 \%)$. The vegetable's farm is not dominant in the scene and present in the middle ground. This suggests that dominancy of the agriculture, in the distance, zones affect the responses score.
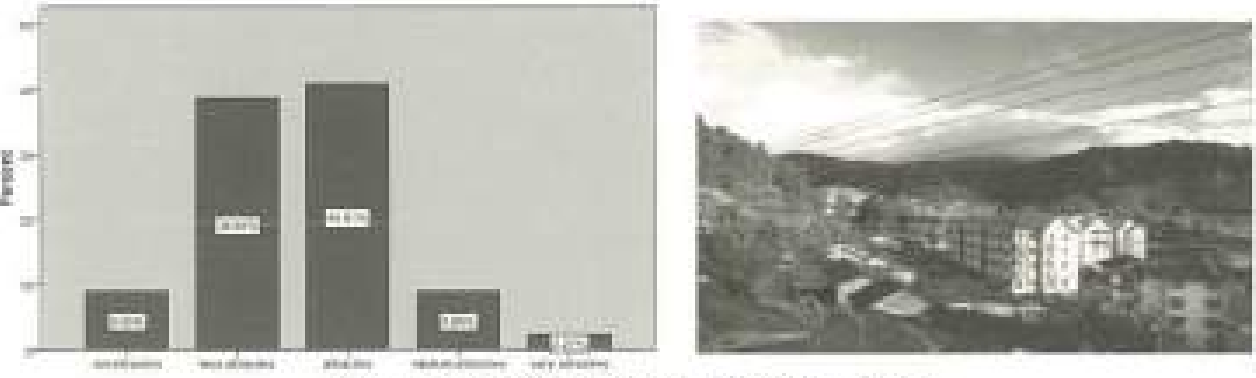

Figure 10(a): Scene at point 56 (Mean 3.55)
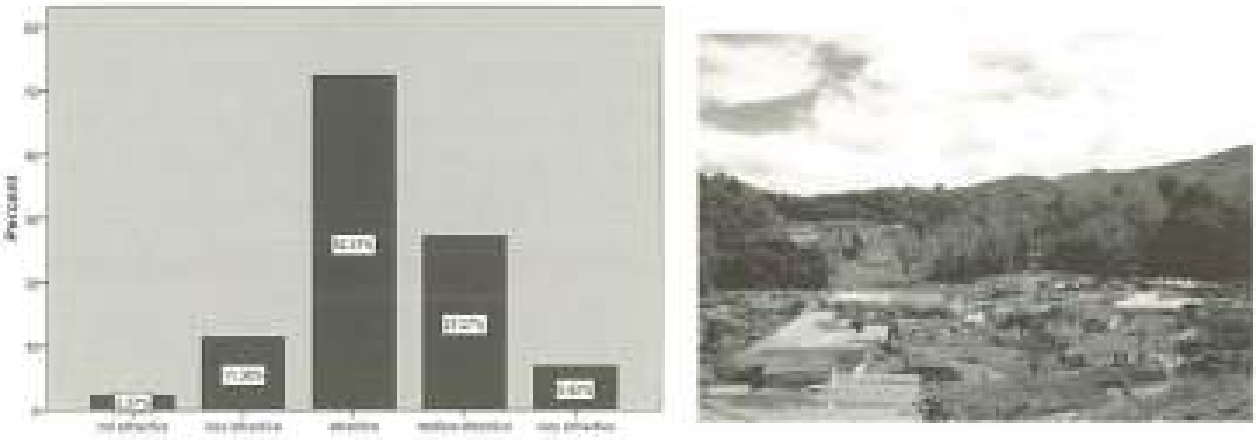

Figure 10(b): Seene at point 43 (Mean 2.57)
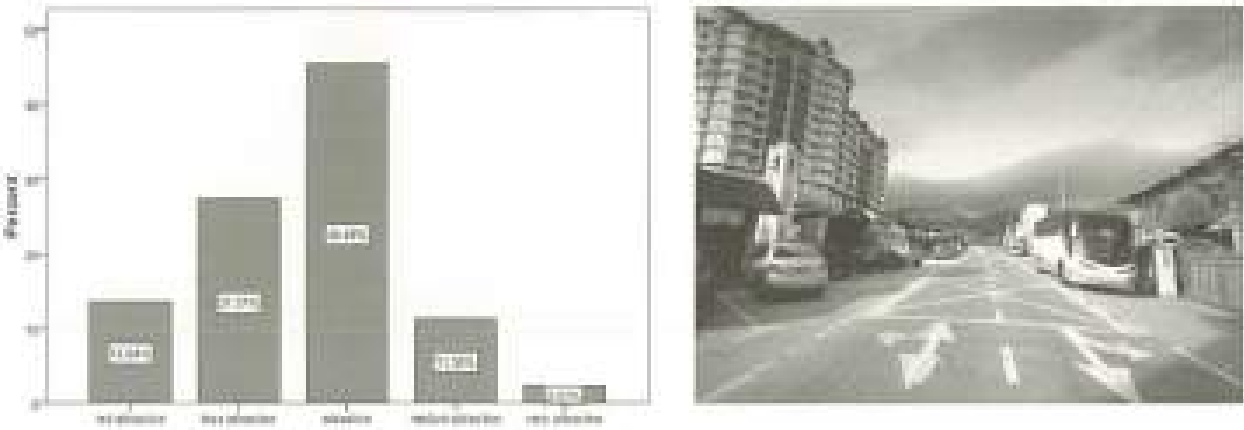

Figure 10(c): Scene ut poimt 38 (Mean 2,61) 
Further analysis for other land use types can be seen in the Figure 10. The three scenes demonstrate visual landscape of the built up area with a scene a (village), scene b (residential area) and scene o (commercial and business area). As we can see all the scenes present dominance built up area. It is present at the foreground and middle ground views. The seene test (a) shows the highest mean score (3.55) as compared to the scene $b(2.57)$ and scene $c$ (2.61). Most of the respondents agreed that all scenes are attractive with the highest percentage of the scene a $(52.27 \%)$. It follows by scene e $(45.46 \%)$ and scene b $(40.91 \%)$. It is found that respondents tend to give high score to village scenery with the moderate attractive $(27.27 \%)$ and very attractive $(6.82 \%)$ than both scenes. The scene $b$ and $c$ demonstrate a similar result where the large pereentage of people feel this scenery is less or not attractive. However, the scene $\mathrm{c}$ shows an intense impression on the seene with the higher percentage on attractive $(45.46 \%)$ and not attractive (13.64\%) than the scene. This suggests the commercial/business area scene is the most unfavourable than residential area view.

\section{CONCLUSION}

In this paper, we have proposed and developed objective measurement criteria of visual landscape features using accessible physical data. The consideration of landscape features in the visual landscape assessment includes topography, landform, water element, and vegetation, as well as positive and negative elements. These can be done through the combination of visual structure of landscape analysis using minimal physical data in GIS application. Validation test for the objective measurement shows that it is acceptable for application ( $\mathrm{p}<0.01$ and moderate association 0.443 ) in supporting expert based assessment on visual landscape. Moreover, the study demonstrates the uniqueness of the area has a moderate correlation with the attractiveness score. This is contradicting with the assumption made for the physical assessment as the uniqueness may be found in the low visual quality. The reason is the uniqueness also can be seen in the scarcity factors where the more rarity the element is the more potential of being unique the area will be.

Correlations of the landscape features and preference scores suggest that the objective measurement criteria have its own limitation. The measurement is bardly to identify the present condition of the visual quality. The visual quality condition provides significant impact to landscape value to eertain landscape features. The analysis shows water follows by vegetation are significantly influcneed by the condition of its quality. However, the study shows the presence of water still provides a positive impact and high scores to the visual landscape value. Further analysis and discussion on the vegetation in 
the study suggests that more detail consideration should be taken for vegetation criteria. Village is more preferable than other built up areas follows by residential area and urban uses. The agriculture views which dominant in the scene is preferable than the agriculture that present in the middle ground view only. It is also found the quality of the agriculture view is influenced by the condition and manageable view, whereas the combination of forest and agriculture at the foreground and middle ground is less attractive (lower value).

The study provides more reliable objective measurement of visual landscape for highlands tourism planning. The method is used to reduce the cost of implementation and provides more details documentation in technical sense to support visual landscape assessment. This will also assist planners for preparing fieldworks in supporting the expert based assessment as well as planning and decision making.

\section{REFERENCES}

Appleton, J., (1975). The Experience of Landscupe London, New York, Sidney, Toroato, John Willey \& Sons.

Aziz, A. and Zainol, N.A. (2009) Local and Foreign Tounst's image of Highlands Tourism in Peninsular Malaysia, Penanika Journal of Social Science \& Humanièty, 17 (1), 33-45.

Bscon, W. R. (1979). The Visual Managenent System of Forext Service, USDA. The national Conference on Applied Techniques for Analysis and Management of The Visual Resources. Nevada.

Ballic, J.E.M. C. Hilton, Taylor, S.N. (2004) 2004 IUCN Red Lixt of Threatened Species A Globul Species Assessment, - Gland, Switzerland and Cambridge, UK: IUCN.

Barbara, C., (1998). The Great Hill Station of Asia. New York. Westview press

Blischke W.R.4 Bush J.W. and Kaplan R.M. (1975). Successive Intervals Analysis of Preference Measures in a flealth Status Index. Healfh Service Retearch. Summer, 10(2):181-198

Brown, T.C. and Daniel, T.C., (1984). Modelling forest scenic beauty. concepts and application to Pondercsa Pine. In: USDA Forest Reseurch Service Rosearch Paper RM-256, Rocky Mountain Forest and Range Experimental Station, Fort Collins, CO.

Buang. S., (2001). Cameron Hightands is dying News Straits Times: www.highbeam.com/doc/1P1-142777601.html (retrieved 21 January 2008)

Clifton, J. (2006). Promoting Sustainable Tourism in the Cameron Highlands: An overview of current issues and some proposal in C.N.Weng. Cameron Highlands: Lsviex and Challenges for sasninable Development (pp. 56-61). Penang: Universiti Sains Malaysia Publication 
Council of Shetland Island (2006). Baxic Principles of Landscupe and Visact Impact Assessment For Sponsors of Developwent: Guidelines.

Countryside Agency and Seottiss Natural Heritage (2002). Landscape Chatacter Assessment: guidance for England and Scotland. htip:/Www.snh.org.uk/wwo/sharinggoodpracticeicci/cci/guidance) (retrieved 21 January 2003)

Countryside Commission (1993) Landiscape Assessment Guidance, (CCP 423).

Countryside Commission (1991).Areas of Outxtundian Natural Beaury: A policy statement. (CCP 302).

Countryside Commission (1987). Landscape Assessment; a Comentryside Commission Approach (CCD 18).

Clay, G. R. \& Daniel, T. C. (2000). Scenic Landscape assessment: The Effects of Land management Jurisdiction on public perception of Seenic Beauty. Landscajoc and Urbun Planuing, $49(1-2), 1-13$.

Craik, K.H. (1972). Appraising the objectivity of landscape assessment. In J.V. Krutilla, Nonural Environments: Studies in Theoresical and Applied Analysis (pp, 292-346), London: Johns Hopkins University Press.

European Commission, (2000). European Lardscape Canvention and Exptanatary Report, Strasbourg: T-latid 6,

European Commission, (2001). A Sustainable Europe for a Better World: A European Union Strategy for Sustainahle Development. Commenication COM(2001)264 final, Brussels, 2001, http//europa.eu int/eur-lex/en/com/cne/2001/ com2001 0264en01.pdf).

European Environmental Agency, (2003). Europe's Environment: The Third Assessment. European Environmental Agency, Copenhagen.

Fui, L.H., Chuen, W. W. and M.P.Mamat, (2006). The Onang Asti and Ecotourism and Develpoment in Cameron Highlands, In C.N.Wenig. Camernon Hishlarids; lssaes and chaflenges for sustainable development (pp. 86-93). Penang: Universati Sains Malaysia Publication.

Galliano, S. J., \& Leeffler, G. M. $(2000)$, Scenery Assessment: Scenic Beaury at the Ecorogion Sczile. Forest Service, US Department of Agriculture . Oregon: Pucific Northwest Restarcls Station.

Gary, R. Clay, Robert, K. Smidt. (2004). Assessing the Validity and Reliability of Descriptor. Landscape and Urbun Plannisy, 6654), 239-255.

Herald, S. (2006). Stice of Eingland Deep in she Jiangle. The Sydney Moming Gerald: hup:/Www.smh com.au'news/asiaslice-of-england-decp-in-thejungle/2006/02/11/1139542439820.html (rotrieved 21 January 2008)

Herzog, R. T. Maguire, C. P. \& Nebel, M. B. (2003), Assessing the restorative components of environments, Journal of Environnerstal Psychology, 23(2), $159-170$.

Higuehi, T, (1984). The Visaal and Spratial Stracture of Landsrape. London: The MIT Press

Hull, R. B. and Revell, G, R. B. (1989). Cross-cultural eompaesson of landscape scentic beauty evaluations: a case study in Bali. Journal of Envinonmental Psyclology. 9:177-191. 
Hull, R., and Stewart, W. (1992), Validity of photo-based scenic beauty judgements. Journal of Environuental Psychology, 2, 7-11.

Jantan, M. L. (2003, Aptil 23). Menories ef Camerons Long Past. HightBeam Research: http//www.hightbeam.com/doc/1P1-82778509.html (Retrieved 8 Jamuary 20018):

Jarvie, C. (2001. November 25) a land where the different cultures blend and the tea leaf is king: The Independent (London, England). Highbeam Reseacth: http//www.highbeam_comidoc/1P2-5207851.html (Retrieved 8 January 2008).

Kumaran, S. and A.N.Ainuddin. (2006). Forests,water and climate of Cameron Highlands, In C. N, Weng, Cameron Highlands Issues and challenges in sastainable sforelopment (pp, 1-8), Penang: School of Humanities, Universiti Sains Malaysta Publication.

Litton, R.B. (1972). Aesthetic Dimensions of the landscape, in J.V.Krutilla, Natural Environments: Stadies Theoretical and Applied Avalysis (pp. 262-291). Londoa: The Johns Hopkins University Press.

Malaysia, N, L (2000), Origin of Place Nanes: Cameron Highlands. Retrieved February 2009, from History of Malaysia: http://sejarahmalaysia.pnm.my!

Malaysia, P. N. (2008). Origin of Place names, History of Malaysia: http:/acjarahmalaysia.pnm.my/ (Retrieved 12 January 2008)

Malaysia Town and Country Planning. (2007), Ensiklopedia Undang-Undang dan pentadbiran perancangan bandar dan desa. http:/ www, townplan,gov my/terbitan,plpp

Mapjabil, J., weng, C N., Mohd Nor, N., \& Ghazali, S. (2007). Highland Tourism in malaysia:Issues and challenges. Proceeding of Seminar Kebangeaan Geografi 2007. Turjung Malim: FSSK Universiti Kebangsaan Sultan Idris, hutp://en.forkus, eom/d/geografi-2007. htm

Mariapan, M., Abdullah, A. M., Muda, A., \& Othman, 1. (2008). Tourist's Perceptions on Highland Management: Cameron Higblands Experience. Ecocity World sumuni 2008 Proceedings (pp. 1-14). San Francisco; Ecocity builders.

Mohaiadin, A. (2003). Cameron Highlands a Fading Beaury: News Straits. Tines Anticle. Highbeam Research: http://www highbeam,com/doc/IPI82752252.himl (Retrieved 7 January 2008)

New Straits Times (2603). Call For Scientific Expedition to The Caneron Hightands.

Palmer, J.F and Hoffman, R.E., (2001). Rating Reliability and Representation Validity in Scenic Landscape Assessment Jownal of Landacape and Urban Plannirg. $54,149-161$.

Robert, R.R., (1979). The Colonial Genesis of Hill stations: the genting exception. American Geographical Sociery, 69(4):463-468

State Govemment of Pahang (2004).Technical Report, Cameron Highands Local Plan 2003-2015. Pabung State Depariment of Town and Country Planning (umpublisied)

State Government of Pahang (2008). Interim Report, Pahang State Structure Plan 20022020. Kuala Lumpur; Pejabat Projek Kuantan, Federal Department of Town and Country Planning (Unpublished) 
Torres, S.A., Cloquell-Ballester, V. \& Darton, R. (2007). Development and Validation of a Multicriteria Indicator for the Assessment of Objective Assthetic Impact of Wind Farms. Renewable and Sursainable Energy Reviews, 13, 40-66.

Vijendra, D. (2006). The role of REACH in environmental conservation-awareness, education \& monitoring In C. N. Weng, Cameran Hightands: Issaes and Chaflenes in Susrainable Deveopment (pp. 12-25). Penang: School of Humanitses, Universiti Sains Malaysia.

Weng, C. N. (2006). Striking Balanse Between Development and Environmental Protection in Cameron Highlands, In C. N. Weng, Cameron Highlands: Issues and Challenges in Sustainable Development (pp. 12-25). Penaag: School of Humanities, Universiti Sains Malaysia.

Zube, E. H., Pitt, D. G, and Anderson, T, W. (1984). Perception and prediction of Seenic Ressurces Values of The Northeast, In E. H. Zube, R, O. Brush, \& J. G. Fabos, Landsrapw Assessment: Values, Perceptions and Resources (pp, 151167). Stroudsburg, Pennsylvania: John Wiley \& Sons, Ine.

Zubs, EH., Sell, J.L and Taylor, J.G. (1982). Landscape Penception: Research appleation, and Theory. Landscape Planning, 9(1), 1-33. 